\title{
Optimization of Presence and Student Assessment with or Code Based on Client Server Android
}

\author{
Agung Prajuhana Purta, Sufiatul Maryana, Samsudin
}

\begin{abstract}
Presence system and student assessment are still many manuals in input and calculation, of course with such a system many shortcomings including extra time in inputting and calculation, the possibility of absent redundancy and cheating absent by the students and the missing or damaged documents presence and assessment students. One of the lecturers' duties is to provide students with a quick and accurate assessment. This research has purpose to make the system of absent and assessment which developed by applying technology of QR Code and Client Server to facilitate in input presence, appraisal and monitoring so that lecturer can more quickly and efficient in making assessment report and student can see directly result of assessment on system. In the implementation, the system performs the QR Code scanning of students present in the lecture so that the input is faster and less likely the occurrence of errors and cheating attendance by students.
\end{abstract}

Index Terms: Presence, Assessment, SQLite, QR Code, Client Server.

\section{INTRODUCTION}

Lectures organized an academic activity at a particular college education institution. Lectures can be shaped lecture / lectures, seminars/discussions, practice, field work, research or simulations. In order lecture activities run smoothly, students are required to attend each academic activities organized by educational institutions [1]. During the recording process absent students using the manual method that is charging a signature on a paper sheet Presence distributed to each lecture. How presence this manual has a weakness with the possibility redundancy and illegal absent undertaken by students as well as the loss or destruction of documents student presence. Student presence is also one of the assessment criteria in the subject. Each semester, the student presence recapitulated then the value is taken from the percentage of student presence during the lectures. Value Presence students will be added to the calculation of the final value in making the course followed by the student. For student assessment system at this time has some drawbacks, such as speed, redundancy and loss assessment documents [2]. Those to overcome the problems contained in the presence and votes better methods are needed in order to facilitate the presence and assessment courses, for more rapid

Revised Manuscript Received on April 25, 2019.

Agung Prajuhana Putra, Department of Computer Science, Faculty of Mathematics and Science, Pakuan University, Indonesia.

Sufiatul Maryana, Department of Computer Technology, Diploma Program, Pakuan University, Indonesia.

Samsudin, Department of Computer Science, Faculty of Mathematics and Science, Pakuan University, Indonesia. and faster assessment process in the search for student grades. Presence and assessment of the problems of students, the authors developed an Android-based system with the title "System_of_Student_Assessment-Based Presence and Android" [3]. The system developed applying the QR Code [4] technology to facilitate the recording of Presence and student assessment in certain subjects. In practice, scanning the QR code lecturer of students who attended the lectures, so a small possibility of fraud illegal absent students. The system developed applying the QR Code technology to facilitate the recording of Presence and student assessment in certain subjects [5]. In practice, scanning the QR code lecturer of students who attended the lectures, so a small possibility of fraud illegal absent students. The system developed applying the QR Code technology to facilitate the recording of Presence and student assessment in certain subjects. In practice, scanning the QR code lecturer of students who attended the lectures, so a small possibility of fraud illegal absent students.

\section{METHODOLOGY}

The research method applied to the manufacture of presence and student assessment system based on android using SDLC method (System Development Life Cycle) which can be seen in Fig. 1.

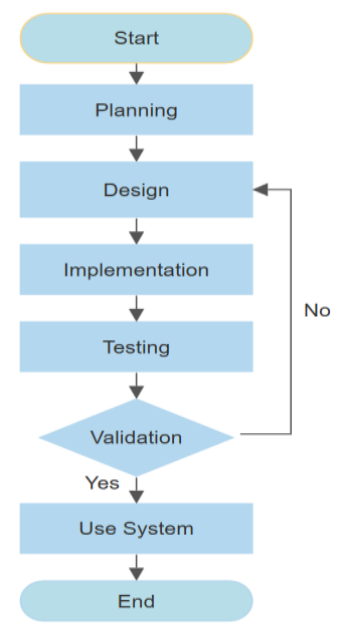

Fig. 1. SDLC method designations 


\section{A. Planning}

The planning stage is to identify needs and determine the purpose of making the system. Aims to simplify the creation of applications with presence and android-based student assessment. Applications created using technologyQR Code with ZXing library for the presence and student assessment on android smartphone and utilize the SQLite database as the database used [6]-[7].

\section{B. Analysis}

Phase analysis to be done is to understand the problem on systems running, and then draw conclusions from the analysis that has been done. The core of analysis stage is to identify problems and to find out the deficiencies in the current system so as to facilitate in designing the system to be built.

\section{Analysis Of The Current System}

System running the analysis phase will be carried out by analyzing the system is running on the presence and assessment in Computer Science Study Program Faculty UNPAK. Where the presence and assessment done still using paper manually. Analysis of the system is running on the presence and assessment can be seen in Fig. 2.

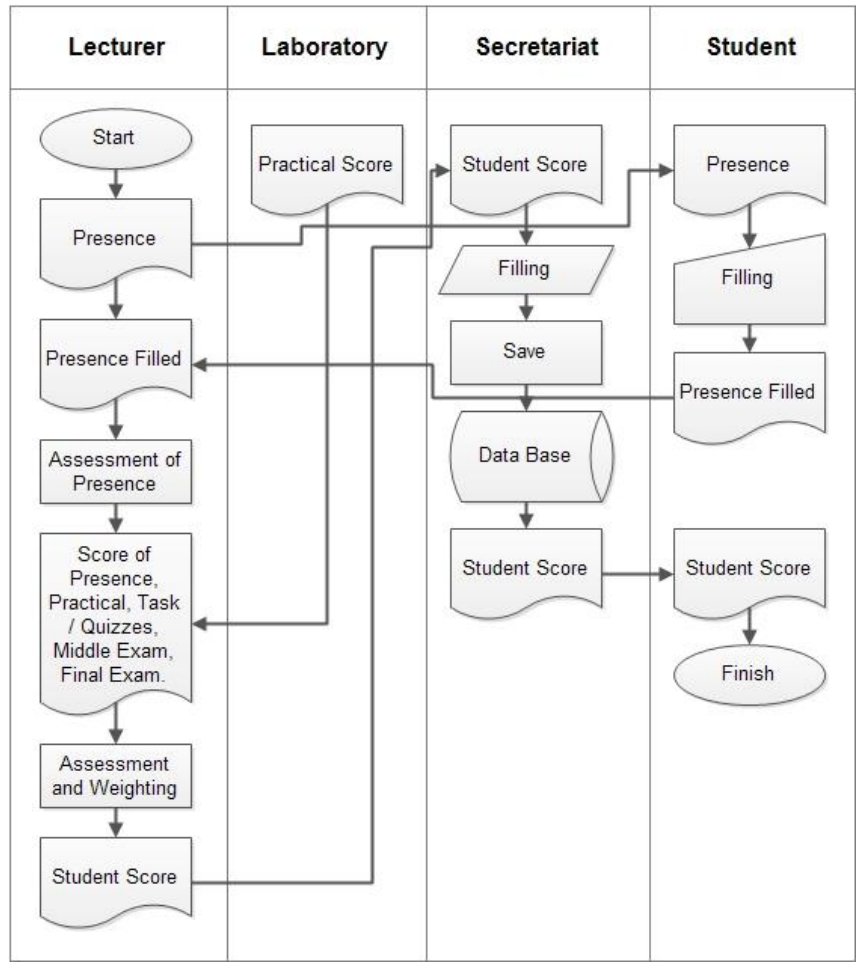

Fig. 2. Flow Chart Diagram System Running

\section{Analysis System To Be Developed}

The current system is still a shortfall in which the possibility of loss or damage to the paper presence and the possibility of illegal absent done by students during presensi do. Therefore, in the system to be developed, will be made android based mobile systems to facilitate the recording of Presence and student assessment in certain subjects. Analysis system to be developed in the presence can be seen in Fig. 3 .

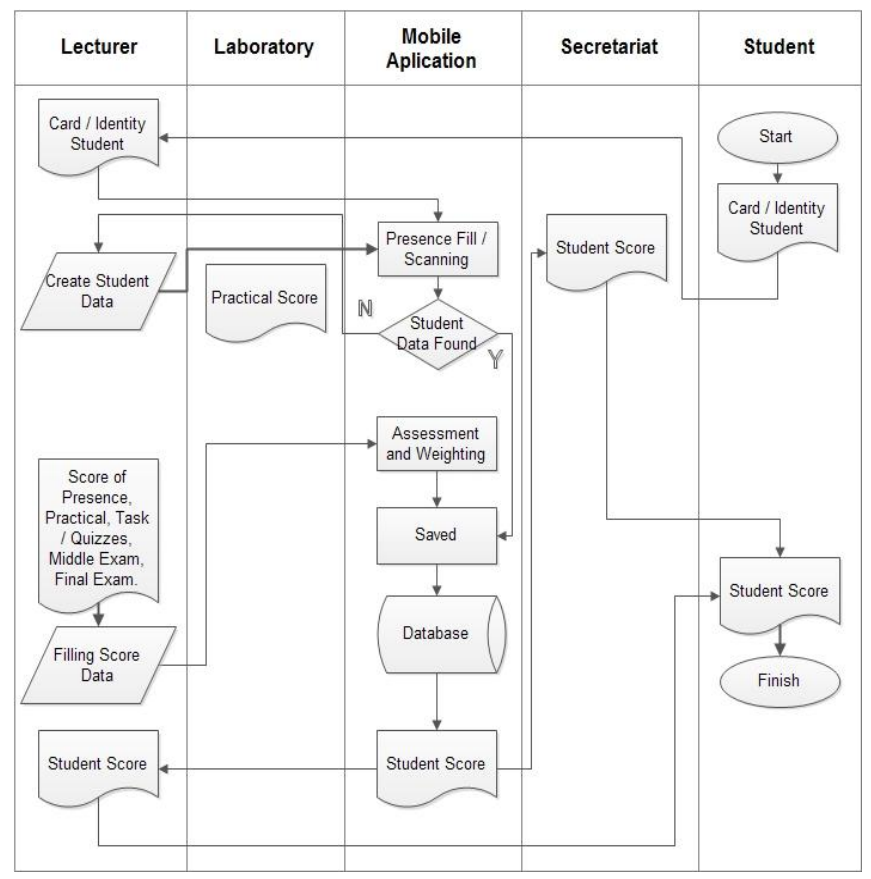

Fig. 3. Flow Chart Diagram System to Be Developed

\section{E. Calculation Formula}

The calculation formula used is a calculation formula in which the value taken on SQLite database previously saved and processed by the Java programming so as to facilitate in the assessment of student quality and value in the form of letters. The formula used is divided into two stages: determining the presence and value of the final value of the courses in the form of letter grades of quality and quality. The calculation formula is obtained from the interview with $\mathrm{Mr}$. Agung Prajuhana Putra, M.Kom as a professor of Computer Science Faculty of Science Program UNPAK.

- Formula Presence

Information :

NPI $=$ Value Presence

$\mathrm{JPM}=$ Number of Student Presence

JPMK = Number of meetings Subjects

NPPi $=$ Value Percentage Presence

- Formula Assessment Course

Information :

$\mathrm{NM}=$ Value Quality

NPI $=$ Value Presence

$\mathrm{NPK}=$ Value Practice

$\mathrm{NPPk}=$ Value Percentage Practice

NTS = Value Assignment

NPTs $=$ Value Percentage Tasks

$\mathrm{Nt}=$ Value Uts

$\mathrm{NPt}=$ Value Percentage Uts

$\mathrm{Na}=$ Value UAS

NPA $=$ Value Percentage UAS 


\section{F. Stage Design}

In the prototype design stage presence and student assessment described a series of visual design of the system it is running as well as the display interface of the system. The method used designs using design tables, flowcharts and design of the display system.

\section{G. Design Database}

In designing database Entity Relationship Diagram [8]- [9] can be seen in Fig. 4. Specifications table prototype Presence and student assessment attached in Appendix 1. Specifications Table.

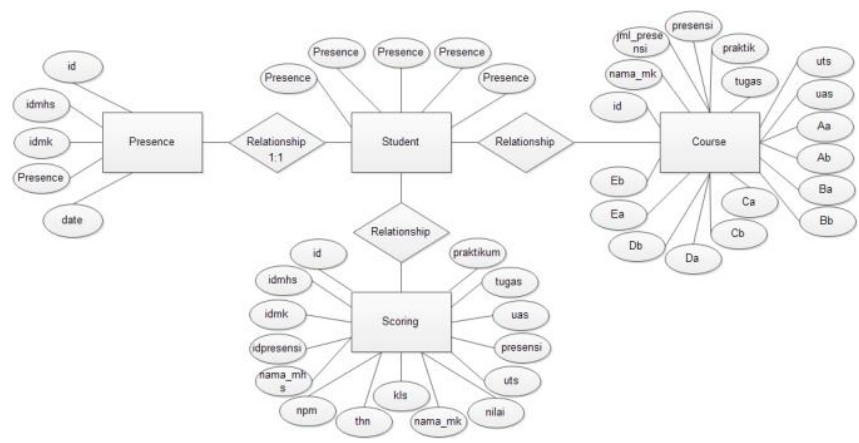

Fig. 4. Entity Relationship Diagram

\section{H. Flowchart System}

Flowchart System is an application program flow in the presence and assessment of students can be found in Appendix 2. Flowchart System,

\section{Implementation Phase}

This stage is the stage where the program will be translated into codes using programming languages in accordance with the design that has been done before. In this stage, the overall creation of applications that will encompass the process of typing programming code in Android Studio to use the Java programming language and database using SQLite.

\section{J. Testing System}

Pilot phase carried out in order to determine whether the system already built to run well or not and whether the application in accordance with the design stage as well as the purpose of the system. For that there are several experiments performed that Test Validation and Testing Compatibility Testing Usability,

\section{K. Stage Of Use}

During the final stage will be the operation of the program which aims to ensure that all needs are met in the application system and the application is already running with the function and the expected goals.

\section{RESULT AND DISCUSSION}

\section{A. Homepage}

The start page is the first look at the first time the application runs on the android operating system. The initial view splash screen in the form of duration of 3 seconds before displaying the main page, start page views can be seen in Fig. 5.

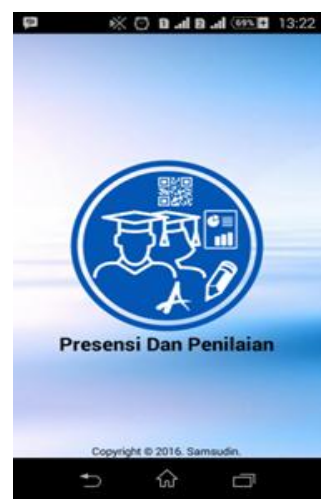

Fig. 5. Homepage

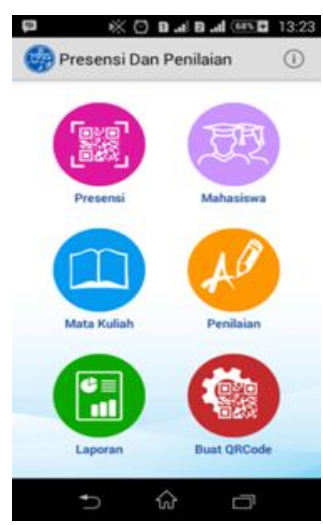

Fig. 6. Main page

\section{B. Main Page}

On the main page of the application, there are 6 (six) main key and 1 (one) button on the top right corner of the app as brief information about the presence and assessment of student applications. The main buttons numbered 6 consisting of Image Button Presence, Image Button Students, Image Button Subject, Image Button Assessment, Image Button Reports and Image Button Create QR Code [10]. The Image Button connected and serves to display the corresponding page Image Button selected. The main page can be seen in Fig. 6.

\section{Weather Presence}

When Image Button Presence on the main page will appear pages dipole then select subjects in order to determine the ongoing courses for student presence. On this page there is also a menu to edit to change the presence of students, the menu is updated to update the list of courses and subjects the search menu. Maps select subjects can be seen in Fig. 7.

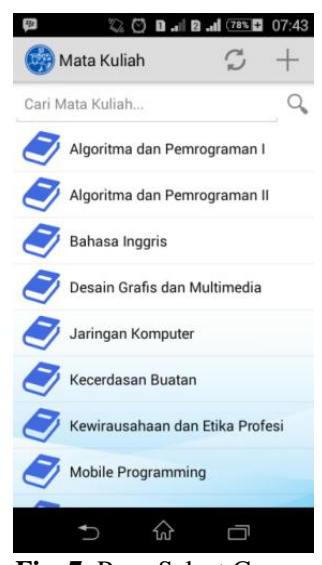

Fig. 7. Page Select Course

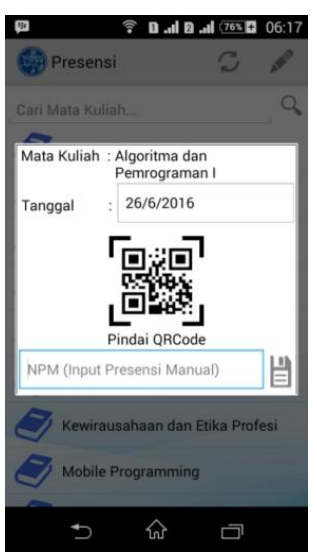

Fig. 8. Presence Confirmation page
If one of the subjects chosen name on the page of the subjects in the Presence menu confirmation page will appear to start scanning QR Code Presence manually or by entering NPM column. This confirmation page displays the name of the selected subjects; dates can be replaced by utilizing a date picker widget on android system, in the form Image Button QRCode button to start scanning and NPM column for user presence. The confirmation page is shown in Fig. 8.

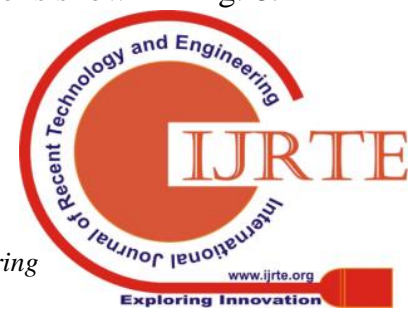


The next page will display a QR Code scanner to function for scanning. On this page there are only the scanning area and menu setting options and assistance. Fig. 9 below is a picture of the QR Code scanner page.

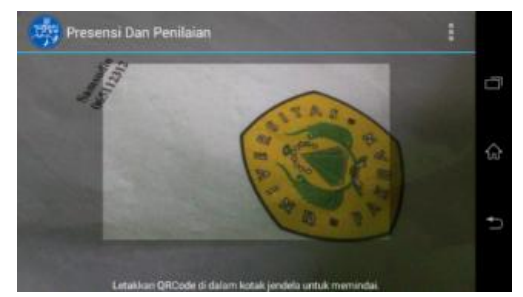

Fig. 9. QR Code Scanner Maps on Mobile

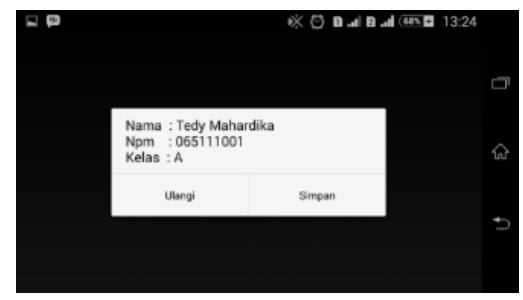

Fig. 10. Maps Save On Mobile

If at the time scanning student data has been found on the SQLite database application, then save the page will appear as shown in Fig. 10.

\section{Students page}

Student pages presented in Fig. 11 is a page that displays a list of all the students who are in database Presence and student assessment. On this page there is also a menu available to add to the students, the menu is updated to update the list of students and student search menu.

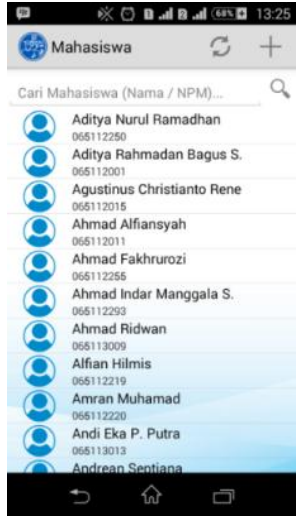

Fig. 11. Students page
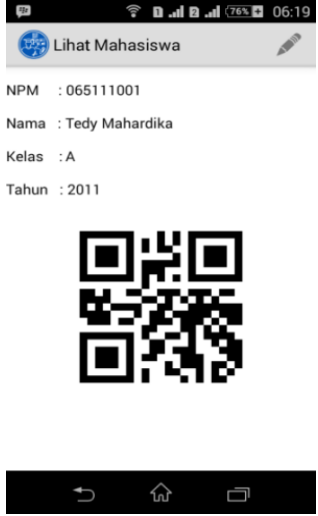

Fig. 12. See pages Students
Fig. 12 is a view student page, on this page show only the information of students accompanied by QRCodeand the edit menu button that serves to transform the student data. Fig. 13 is a plus pages and change the student database and assessment presence. On this page there is a form fill and 2 buttons that function to save and exit pages and change the student added.

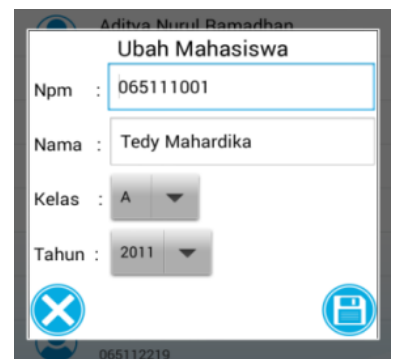

Fig. 13. Maps Add and Change Students

\section{E. Course Maps}

Weather subjects display a list of subjects contained in the database. Page course there is also a renewed menu to update the list of courses, the menu is available to add to the data subjects in the database and search menu course by course name. See page of courses is to see detailed information on the course and only have to change the menu to change the data from subjects in accordance subjects are shown. Weather-added subjects serves to add new subjects, this page displays the contents of the form and save menu to save it into the database. Weather change the course will display the form containing the data subjects that have been found in the database. This page serves to change the data subjects by pressing the menu button to save. Weather subjects,

\section{F. Weather Ratings}

On the page there is a page assessment select courses that displays a list of subjects, after one of the subjects selected, then it will show a page in accordance with the student and class forces. Page list of students who can be seen in Fig.14 serves to select students in the assessment.

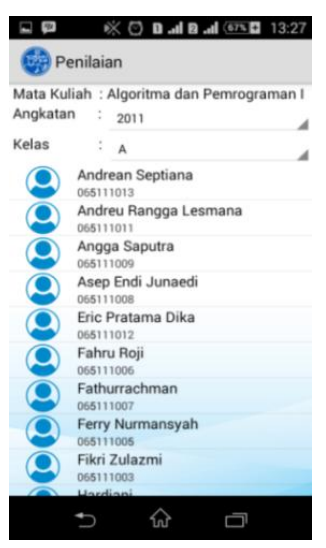

Fig. 14. Page Students Based on Force and Class

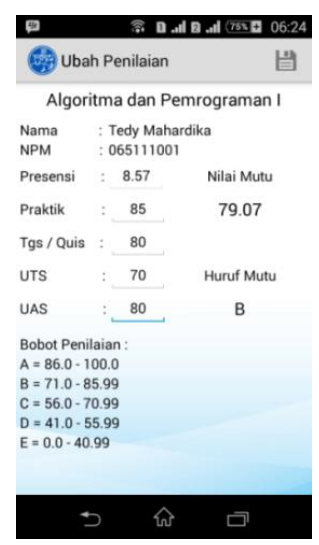

Fig. 15. Weather Assessment and Change Assessment Students
Ratings page is a page that serves to store student assessment, on this page are appraisal forms and save menu to save the data assessment. Change page is a page to change the assessment data already stored on the data base, on this page there is a menu Save to save the assessment data in a way to update the assessment data. Weather ratings and ratings change can be seen in Fig. 15. 


\section{G. Weather Report}

Weather reports broken down into three main parts: the report page by students, classes and courses. Weather reports in the student category displays a list of courses taken and letters obtained quality assessment and will appear after selecting a category and a student on the student list page. Weather reports based on categories of students can be seen in Fig.16.
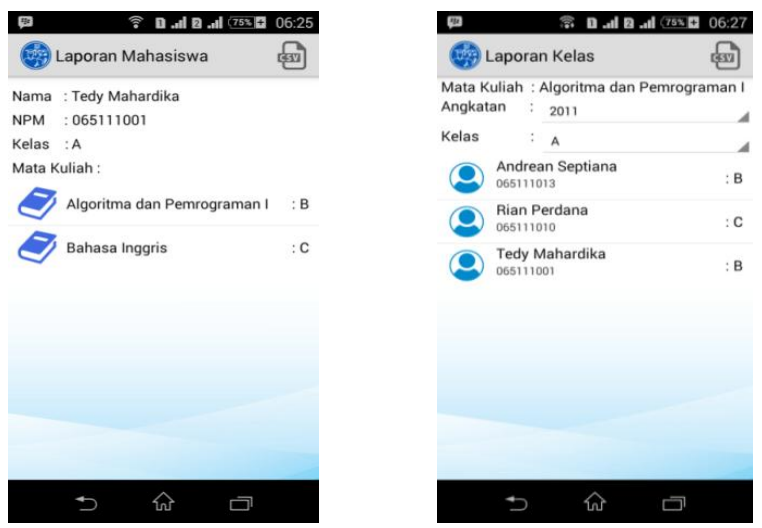

Fig. 16. Student Category Report page Category Class

Page report on class categories presented in Fig. 17 is a report that displays a list of students who have obtained judgments. In the picture, there are 17 courses name information, the choice of the force and classrooms and a list of students who have grades.

On the menu reports by category subjects report a list of students, the menu is updated and the search menu. List students are all students who take the classes with the same subjects. Page list of student assessment in the category of subjects can be seen in Fig. 18.

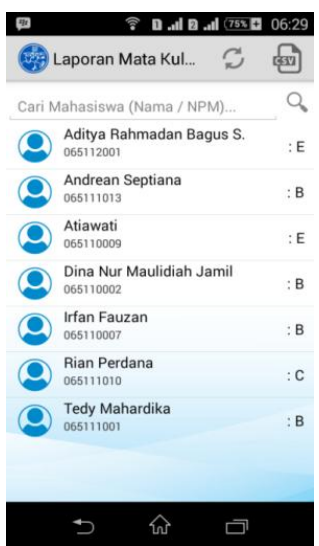

Fig. 18. Weather Report Category Subjects

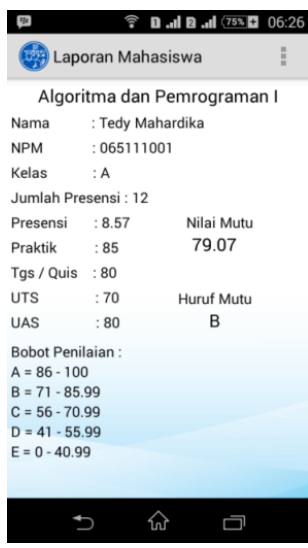

Fig. 19. Student Assessment Details page
Student assessment detail page is presented in Fig. 19 is a page that displays detailed information about student assessment. On the detail page assessment form contained a detailed assessment results, delete menu to delete data assessment and export csv to create an excel file reports. This assessment detail page can be accessed in each report category.

\section{H. Page Create QR Code}

Weather for QR Code an additional function in the presence and assessment applications. On the page there is a form for the QR Code to enter the NPM Edit Text to be encoded by ZXing library by pressing the menu button for QR Code. The result of this encode that serve as a trigger for the presence of students. On this page there is also a save menu to save the image encoded in the phone's internal memory. Weather for QR Code can be seen in Fig. 20.

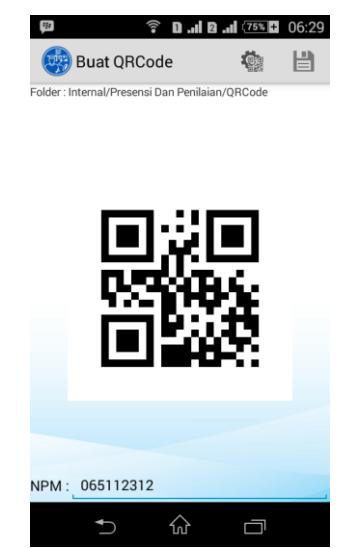

Fig. 20. Page Create QR Code

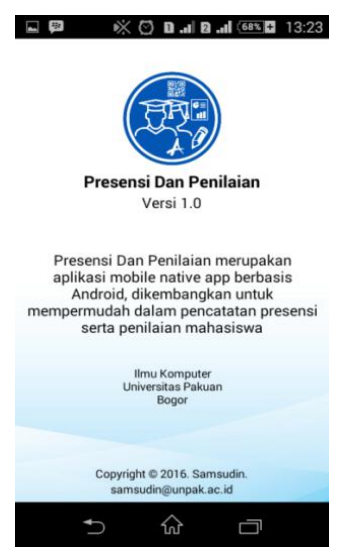

Fig. 21. Weather on Application

\section{On Page}

A page featuring the logo of the application, application name, version of the application, a brief description and information developers about can be seen in Fig. 21.

\section{J. Test Validation}

The test is a validation of the tests conducted to determine the data in the application process if providing valid data or not the manual process. The first validation trials is to test the value of presence of the system and compare with the calculation of formulas manually and the system to obtain the same value between manual and electronic calculation. Fig. 22 shows the presence of application value.

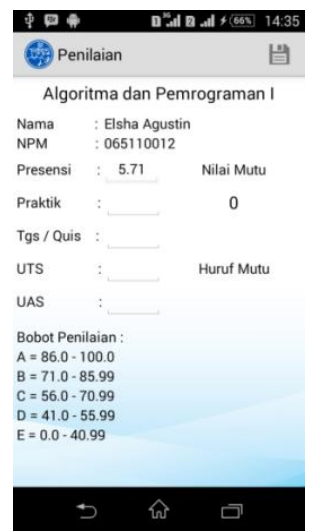

Fig. 22. Page Create QR Code

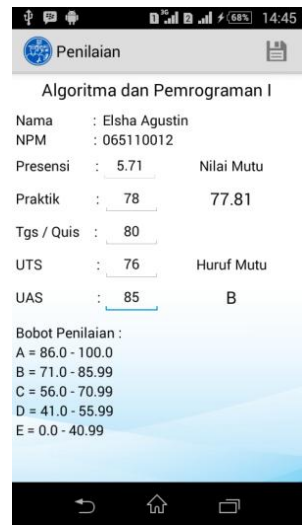

Fig. 23. Weather on Application 
The second trial validation of student assessment test by determining the value and weight of each indicator then calculate the appropriate assessment formula used manually and systems. The value obtained in accordance with the system of manual calculations. Fig. 23 shows the results of the assessment of the application.

\section{K. Compatibility Trial}

The test compatibility test is performed to determine the compatibility of the application of some android devices that have different specifications. Here are the results of a test of compatibility with two smartphone and a different tablet.

- In the first smartphone Samsung Galaxy Chat B5330 with the following specifications, the Android v4.0.3 (Ice Cream Sandwich), 3-inch screen, 4 GB of internal memory, 512 MB RAM, 2 MP rear camera.

- In the second tablet SPC P6 Turbo with the following specs, Android v5.1 (Lollipop), 7-inch screen, 4 GB of internal memory, 512 MB RAM, 5MP rear camera.

- In the third smartphone Sony Xperia M2 Aqua with the following specifications, the Android v5.1.1 (Lollipop), 4.8-inch screen, 8 GB of internal memory, 1 GB RAM, 8 MP rear camera.

Table 1. Testing Compatibility

\begin{tabular}{|c|l|l|l|}
\hline No & \multicolumn{1}{|c|}{ Mobile } & \multicolumn{1}{|c|}{ Camera } & \multicolumn{1}{c|}{ Result } \\
\hline 1 & Samsung Galaxy Chat B5330 & $2 \mathrm{MP}$ & Compatible \\
\hline 2 & SPC P6 Turbo & $5 \mathrm{MP}$ & Compatible \\
\hline 3 & Sony Xperia M2 Aqua & $8 \mathrm{MP}$ & Compatible \\
\hline
\end{tabular}

The results of the compatibility test using two smartphones and one tablet with different specifications can be concluded that the application will run optimally with a minimum specification of Android smartphones v5.1 (Lollipop), 4.5-inch screen, $8 \mathrm{~GB}$ of internal memory, $1 \mathrm{~GB}$ ram, $5 \mathrm{MP}$ rear camera.

\section{Usability Testing}

Applications need to be evaluated users to measure the quality of the application that is using questionnaires Software Usability Measurement Inventory (SUMI). SUMI questionnaire consists of 48 questions. SUMI questionnaire used to measure the quality of use of the software by trial users when using such software [11].

According [2], there are five important aspects that need to be measured, namely efficiency, efficiency, Affect, helpfulness, control and learnability. These five aspects are included on the questionnaire SUMI. SUMI questionnaire statement can be seen in Table 2. The score of each response given different weights for each. Statements that leads more positive towards the system was given a value of 4, 2, 0 for responses agree, do not know, and did not agree.
Table 2. Score Questionnaire Statement SUMI

\begin{tabular}{|c|c|c|c|c|c|}
\hline \multirow[b]{2}{*}{ Statement } & \multicolumn{5}{|c|}{ Score } \\
\hline & 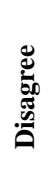 & 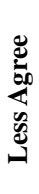 & 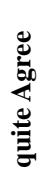 & 总 & 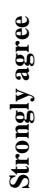 \\
\hline $\begin{array}{l}20 \text { the statement is positive, } \\
\text { example the numbers: } 2,3 \text {, } \\
7,11,12,14,16,18,22,25 \text {, } \\
27,28,29,31,32,34,37 \text {, } \\
40,42 \text {, and } 46\end{array}$ & 0 & 1 & 2 & 3 & 4 \\
\hline $\begin{array}{l}28 \text { negative statement, } \\
\text { namely numbers: } 1,4,5,6 \text {, } \\
8,9,10,13,15,17,19,20, \\
21,23,24,26,30,33,35, \\
36,38,39,41,43,44,45, \\
47, \text { and } 48\end{array}$ & 4 & 3 & 2 & 1 & 0 \\
\hline
\end{tabular}

SUMI questionnaire measurement numeric with scale $0-100$ votes and will be compared with the average user satisfaction score of database SUMI is 50. If the result of the measurement of each category of less than 50 means that the score is still below average, so it needs to be improved to improve the quality of the applications that have been created. Testing is done by testing the presence and assessment of student applications by 6 lecturers Program of Computer Science Faculty UNPAK as potential users of the application. In Table 3 lists QUESTIONS SUMI questionnaire that has been grouped by category aspect usability.

Table 3. Questionnaire Score Calculation SUMI

\begin{tabular}{|c|c|c|}
\hline Category & $\begin{array}{c}\text { The Revelation } \\
\text { Numbers }\end{array}$ & Calculation Score \\
\hline efficiency & $\begin{array}{c}1,8,15,17,28,32,34, \\
37,39 \text { and } 47\end{array}$ & Total proceeds score *2.5 \\
\hline Affect & $\begin{array}{c}2,7,11,16,21,26,30, \\
35,40 \text { and } 45\end{array}$ & Total proceeds score *2.5 \\
\hline helpfulness & $\begin{array}{c}3,10,12,14,22,27, \\
29,36 \text { and } 46\end{array}$ & Total proceeds score *2.5 \\
\hline control & $\begin{array}{c}4,6,13,18,19,20,23, \\
31,41 \text { and } 44\end{array}$ & Total proceeds score *2.5 \\
\hline learnability & $\begin{array}{c}5,9,24,25,33,38,42, \\
43 \text { and } 48\end{array}$ & Total proceeds score *2.5 \\
\hline Global & \multicolumn{2}{|c|}{$\begin{array}{c}\text { Grand total of the total } \\
\text { score per category } * 0.5\end{array}$} \\
\hline
\end{tabular}

After the user completes the task scenario given in the user experience measurement method, the user is required to provide feedback every statement of SUMI questionnaire. Score the results of usability evaluation using SUMI questionnaire can be seen in Table 4 and graphically in Fig. 24 . The final score of each category obtained from the median of each score sequences provided by the user. 
Table 4. Evaluation SUMI

\begin{tabular}{|c|c|c|c|c|c|c|}
\hline 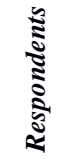 & 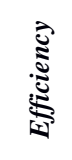 & 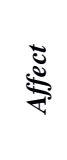 & 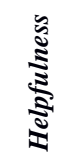 & 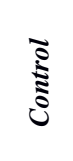 & 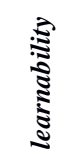 & $\frac{\overrightarrow{0}}{\frac{0}{0}}$ \\
\hline 1 & 65 & 72.5 & 65 & 67.5 & 80 & 70 \\
\hline 2 & 82.5 & 95 & 75 & 92.5 & 85 & 86 \\
\hline 3 & 65 & 67.5 & 65 & 72.5 & 62.5 & 66.5 \\
\hline 4 & 72.5 & 72.5 & 65 & 62.5 & 70 & 68.5 \\
\hline 5 & 65 & 67.5 & 67.5 & 57.5 & 60 & 63.5 \\
\hline 6 & 60 & 77.5 & 57.5 & 57.5 & 55 & 61.5 \\
\hline Median & 65 & 72.5 & 65 & 65 & 66.25 & 67.5 \\
\hline
\end{tabular}

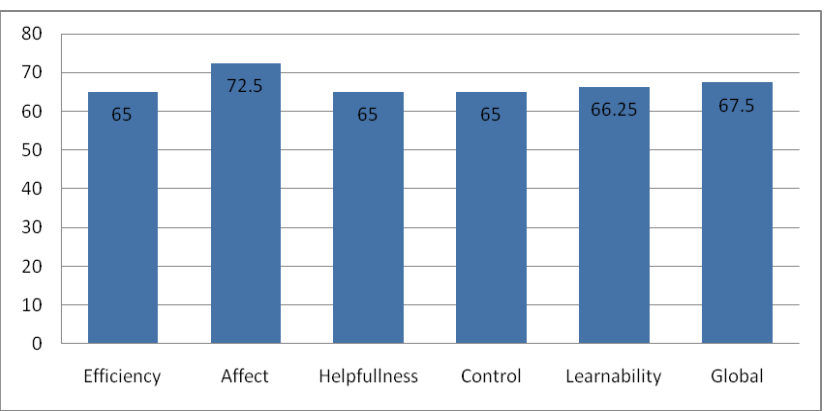

Fig. 24. Evaluation Results with SUMI questionnaire

Based on the results of the evaluation questionnaire known SUMI score of each indicator is efficiency value score 65, Helpfulness value score 65, The control value score 65, learnability value score 66.25 and the highest score on the indicator Affect value score 72.5 and the global score was 67.5, In Fig. 44, it can be seen that in all the categories of usability and global score is above the average score, which is 50. This indicates that the user is satisfied with the application that has been made. So we can conclude Presence application and assessment of students are eligible to be used.

\section{USE}

At this stage presence and student assessment application is ready for use, an application called "app-debug" and the file name can be changed. Presence application files and folders assessment can be taken on android project the project directory: absent and assessment $\backslash$ app $\backslash$ builds $\backslash$ outputs $\backslash$ apk. These applications can run normally on android system with at least Android version 4.0.3.

Trials have been conducted using emulator Samsung Galaxy S2 Android v4.1.1 (Jelly Bean) with a screen resolution of 480x800 pixels at Genymotion software version 2.6.0 and Smartphone Sony Xperia M2 Aqua D2403 Android v5.1.1 (Lollipop) screen resolution 4.8 "(540 x 960 pixels) camera 8 MP. Comparison on every page view, forms, menus and buttons in the application using the emulator and smartphones running accordingly based on the design and testing of validation. every function of database manipulation and calculation runs fine on the emulator or smartphone, while for the scanning function QRCode only be done on a smartphone just because the poor compatibility between camera notebook with the emulator.

In the presence and use student assessment application, make sure the input at android language and the English language to avoid force close error on the application because of differences in decimal format. Decimal format on android with the English language using the symbol of a period (.), The Indonesian language uses symbols decimal comma (,) while the calculation on page student assessment using decimal format by using the symbol of a period (.).

\section{CONCLUSION}

Presence applications and android-based student assessment is built using the Java language with SQLite database, this application is built using Android Studio version 1.5.1 as an IDE development. By utilizing the ZXing library for use QR Code presence of this application can be easily used by lecturers, especially lecturers in the Faculty of Computer Science Study Program University of Pakuan Bogor.

This application form Android Package installation (.apk) that can be installed and running as well as it works well on hand phone android operating system, a minimum of Android v4.0.3 (Ice Cream Sandwich), 4 GB of internal memory, 512 MB ram 2 MP rear camera up to the latest android version and the phone supports the use of a rear camera that will be used when scanning QR Code.

Based on the testing that has been done, presence applications and student assessment can facilitate teachers in making student grades or ratings based courses or classes with effective and efficient. With this application, the lecturer can add, view, edit, search and make a report in the form of a recapitulation of the value much faster.

\section{SUGGESTION}

The shortcoming of this system is the absence of application backup data so that it is possible in case of loss or damage to the phone, presence and assessment data loss due to reinstall the phone. This can cause significant losses where data Presence and student assessment will be lost.

Therefore, it is expected the further development of the application and assessment of student presence so much better with the development as follows:

1. Adding a database backup functions to different devices or upload google drive so that if the phone is lost or damaged, the database presence and student assessment remains.

2. Developed Presence and student assessment system can export and import database, so the distribution of value can be much more easily accessible by the department, faculty and students.

The addition of student data is developed by means of import data into the application absent students and student assessment. 


\section{REFERENCES}

1. A. H. Setyawan, K. I. Satoto and R. R. Isnanto. "Perancangan Aplikasi Sistem Presensi Mahasiswa Menggunakan Qr Code Pada Sistem Operasi Android." Transient, vol. 2, no. 2, pp. 241-246, 2013.

2. N. Bevan and M. Macleod. "Usability measurement in context." Behaviour \& information technology, vol. 13, no. 1, pp. 132-145, 1994.

3. Hamida. PTN Using Site Development and Evaluation of Usability Engineering Usability with SUMI questionnaire. Magister Thesis, Bogor Agricultural Institute, 2013.

4. N. Rumi. "Making Applications Quick Response Code on Student Identity Card”. Student Science Journal, vol. 4, no. 1, p. 115-123, 2015

5. A. Qashlim and H. Hasruddin. "Implementasi Teknologi QR-Code Untuk Kartu Identitas.” Jurnal Ilmu Komputer, vol. 1, no. 2, 2016.

6. H. Andtonio. "Design Administration System Informasi (SI-ADIF)." Elkha Journal, vol. 4, no. 2, pp. 12-15, 2012.

7. D. Pratiwi. Quick Techniques Mastering PHP My SQL in Time Is Very Short Once Read Inget Mastering PHP MySQL Jump in Instant Without Teachers. Jakarta: KunciKom, 2012

8. B. Herman. Mastering Java 2 \& Object Oriented Programming. Yogyakarta: Andi Publisher, 2004.

9. A. A. Huda. Live Coding! 9 Android Application Homemade. Yogyakarta: Andi Publisher, 2013.

10. N. M. Taqwa. "Assistant Lecturer Attendance System Using QR Code Scanner Android Based on Information System Studies Muria Kudus University." In Proceedings Seminar Nasional Teknologi dan Informatika, pp. 1-10, 2015.

11. E. Veenendaal. "Questionnaire Based Usability Testing." In Proceedings of the European Conference Software Quality Week, pp. 1-9, 1998. 